\title{
ACQUIRED CHOLESTEATOMA IN CHILDREN AND ADULTS - A CLINICO-PATHOLOGICAL AND IMMUNOHISTOCHEMICAL STUDY OF ITS CHARACTERISTICS
}

\author{
P. Benjamin Kumar ${ }^{1}$, K. Srinivas ${ }^{2}$ \\ ${ }^{1}$ Assistant Professor, Department of ENT, Government ENT Hospital, Koti, Attached to Osmania Medical College, Hyderabad. \\ ${ }^{2}$ Assistant Professor, Department of ENT, Government ENT Hospital, Koti, Attached to Osmania Medical College, Hyderabad.
}

\section{ABSTRACT}

\section{BACKGROUND}

Cholesteatoma $(\mathrm{CH})$ is a bag-like cystic structure developing in the middle ear cleft, either following a retraction pocket or epithelial migration or metaplasia. It forms in Chronic Suppurative Otitis Media (CSOM) of attico-antral type. Though the pathogenesis of $\mathrm{CH}$ is same in adults and children, its clinical presentation is more aggressive in the latter. Many factors play their role in producing osteolytic changes in the walls of middle ear cleft. One among them is an evidence of cellular histochemical reactions initiated by enzymes, bacterial proteins and toxins liberated following lysis of the organism.

The aim of this study is to compare the histopathological structure and immuno-histochemical characteristics of acquired cholesteatoma in children and adults.

Study Design - Prospective clinical study in tertiary care centre.

\section{MATERIALS AND METHODS}

86 patients presenting with clinical diagnosis of CSOM with cholesteatoma are included; 35 patients belonged to the age group below 18 years and the remaining 51 were above 18 years. Patients were examined under microscope, audiometry and peroperative assessment of the disease was done. Tissue specimens were collected per-operatively and preserved for histopathological examination and immuno-histochemical technique (PCNA monoclonal antibody).

\section{RESULTS}

HPE study showed layers of stratified squamous epithelium with the underlying tissue fibrosis in adults when compared to children, which was significant statistically with a p value 0.015 . High infiltrations of inflammatory cells were seen in both adults and children. Immuno-histochemical examination revealed higher expression scores of proliferation markers significant statistically with $\mathrm{p}$ values of 0.0054 ( $\mathrm{p}$ value taken as significant $<0.05$ ).

\section{CONCLUSION}

The adult CHs showed reparative process in the form of fibrosis, but equal inflammatory infiltration as found in Children. The higher PCNA values in matrix and peri-matrix epithelium of children may be correlated to more aggressive and invasive nature of the cholesteatomas.

\section{KEYWORDS}

Cholesteatoma, PCNA, Inflammation, Matrix, Perimatrix, Children, Adult.

HOW TO CITE THIS ARTICLE: Kumar PB, Srinivas K. Acquired cholesteatoma in children and adults - a clinico-pathological and immunohistochemical study of its characteristics. J. Evolution Med. Dent. Sci. 2017;6(3):163-166, DOI: 10.14260/Jemds/2017/40

\section{BACKGROUND}

Collection of desquamated keratin in the center with multiple layers of squamous epithelium (Matrix) surrounded by mesenchymatous granulation tissue (Perimatrix) growing in the middle ear cleft in acquired type of CSOM may progress to produce osteolysis in its vicinity. ${ }^{1} \mathrm{CH}$ may also develop in other parts of temporal bone. The perimatrix of the $\mathrm{CH}$ shows the intense cellular activity converting the dormant osteoclasts to produce osteolysis. ${ }^{2,3,4}$ The center of activity of $\mathrm{CH}$ is the contact zone between matrix and perimatrix.

Financial or Other, Competing Interest: None.

Submission 04-12-2016, Peer Review 28-12-2016,

Acceptance 04-01-2017, Published 09-01-2017.

Corresponding Author:

Dr. P. Benjamin Kumar

Assistant Professor,

Department of ENT

Government ENT Hospital, Koti, Hyderabad,

Attached to Osmania Medical College, Hyderabad.

E-mail: pbenzrk@yahoo.co.in

DOI: $10.14260 /$ jemds $/ 2017 / 40$

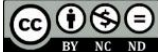

Presence of budding capillaries, immature fibroblasts, acute inflammatory infiltrates in perimatrix.5,6,7,8 $\mathrm{CHs}$ have the potential to destroy the skull bones in its vicinity including ossicles and bony labyrinth.6,9 Cholesteatomas occurring in children are usually observed to have an aggressive spread and frequent growth pattern and higher recurrence rate than those observed in adults. ${ }^{10}$ The present study is an attempt to compare the different clinical and histopathological changes of $\mathrm{CH}$ in adult and paediatric patients to understand the reason for this increase, which was poorly understood.

\section{MATERIALS AND METHODS}

The present study was conducted at Government ENT Hospital attached to Osmania Medical College, Hyderabad. The study period was between May 2012 and April 2014; 86 patients were included in the study out of 11326 patients attending with CSOM during this period. Group A consisted of 35 patients aged below 18 years and Group B consisted of the remaining 51 patients aged above 18 years. 


\section{Inclusion Criteria}

Patients diagnosed to have $\mathrm{CH}$ on microscopic examination of the ear. Patients showing per-operatively with presence of distinctive perimatrix and matrix to be collected as tissue specimens.

\section{Exclusion Criteria}

Patients with congenital $\mathrm{CH}$. Patients with limited $\mathrm{CH}$. All the patients were explained of the procedure and a written consent obtained. Institutional Ethical Clearance Certificate was obtained. Demographic data of the sample of patients was elicited. A thorough history of otorrhoea and loss of hearing was obtained. Microscopic examination of the ears in the OPD was done to select appropriate patients for the study. Audiological evaluation and surgical profile was done. All the patients admitted for $\mathrm{CH}$ surgery were subjected to CT scan of the temporal bones to evaluate pre-operatively the status of dural plate, sinus plate, facial nerve and labyrinthine fistulae. Patients were subjected to modified radical mastoidectomy (Canal Wall Down - CWD) and CHs were removed. During surgery the peri-matrix and matrix were identified and specimens collected into 10\% Formalin solution to fix the tissue. The status of the ossicular chain was graded according to standard classification. All the specimens were prepared and reported by a single pathologist who was blinded about the nature of the tissue. The tissue sections were studied under Haematoxylin and Eosin stain (HPE), Masson Trichrome for the assessment of the degree of fibrosis and immuno-histochemical technique for PCNA (Proliferating Cell Nuclear Antigen) monoclonal antibody [PC10 (anti-PCNA]. The immuno-histochemistry staining was performed using the peroxidase-antiperoxidase method. To compare the results of two groups of patients Easy Fisher test exact test was used as statistical test of significance to compare the degree of fibrosis and inflammation and PCNA expression. A p value below 0.05 was taken as statistically significant.

\section{RESULTS}

In the Group A patients (35), there were 27 males and 8 females. Among the Group B (51), 36 were males and 15 were females. All patients underwent surgery for an acquired middle ear cholesteatoma. The operative specimens from all patients were collected. Group A patient's mean age was $7.2 \pm$ 2.4 (Age range: 5 to14 years). Group B patient's mean age was $28.62 \pm 6.2$.

(Age range: 15 to 43 years), (Table 1 ).

\begin{tabular}{|c|c|c|c|c|}
\hline Groups & Male - 27 & Female - 08 & Age Group & Number \\
\hline \multirow{2}{*}{ Group A } & 07 & 04 & $05-09$ Yrs. & 11 \\
\cline { 2 - 5 } & 16 & 08 & $10-14$ Yrs. & 24 \\
\hline \multirow{3}{*}{ Group B } & Male - 36 & Female - 15 & & \\
\cline { 2 - 5 } & 09 & 05 & $15-24$ & 16 \\
\cline { 2 - 5 } & 10 & 07 & $25-34$ & 19 \\
\cline { 2 - 5 } & 17 & 03 & $35-44$ & 20 \\
\hline
\end{tabular}

Table 1. Showing the Age and Gender Incidence $(n=86)$

In Group $\mathrm{A}$, attic perforation was observed in 12 (34.28\%), Posterior marginal perforation in 7 (20\%) and large central perforation in 16 (45.71\%) patients. In Group B, patient's attic perforation was observed in 24 (47.05\%), posterior marginal perforation in 18 (35.29\%) and large central perforation in 17 (33.33\%) patients. History of loss of hearing was observed in both the groups, but better expressed by the patients of Group B. The type of hearing loss was mixed in nature on audiometry in both the groups. The Pure Tone Averages (PTA) of Air Conduction (AC) hearing were $40 \mathrm{~dB}$ to $55 \mathrm{~dB}$ in 13 patients (37.14\%) and $56 \mathrm{~dB}$ to 65 $\mathrm{dB}$ in 22 patients (62.85) of Group A. The hearing loss among higher frequencies; $3000 \mathrm{KHZ}$ to $6000 \mathrm{KHZ}$ in Group A was 50 $\mathrm{dB}$ to $75 \mathrm{~dB}$. The PTA of AC hearing was $30 \mathrm{~dB}$ to $45 \mathrm{~dB}$ in 29 patients $(56.86 \%)$ and $46 \mathrm{~dB}$ to $50 \mathrm{~dB}$ in 22 patients $(43.13 \%)$ of Group B; the hearing loss among higher frequencies; $3000 \mathrm{KHZ}$ to $6000 \mathrm{KHZ}$ in Group B was $45 \mathrm{~dB}$ to $50 \mathrm{~dB}$. Total Hearing Loss (THL) was observed in 3 patients of Group A and none in the Group B. In Group A patients the extent of $\mathrm{CH}$ was limited to attic in 4 patients $(11.42 \%)$, limited to attic and antrum in 7 patients $(20 \%)$ and involvement of middle ear cleft and entire mastoid air cells up to the tip in $24(68.57 \%)$. In Group B patients the extent of $\mathrm{CH}$ was limited to attic in 18 patients (35.29\%), limited to attic and antrum in 13 patients (25.49\%) and involvement of middle ear cleft and entire mastoid air cells up to the tip in 20 (39.21\%). The difference in terms of percentage of destruction of Group A patients was higher (88.57\%) compared to $64.70 \%$ in Group B. Ossicular erosion was showing higher grades of involvement in Group A (80\%) compared to Group B (60.78\%) (Table 2).

\begin{tabular}{|c|c|c|c|c|}
\hline \multirow{2}{*}{ Observation } & \multicolumn{2}{|c|}{ Group A } & \multicolumn{2}{c|}{ Group B } \\
\cline { 2 - 5 } & No & $\mathbf{\%}$ & No & \% \\
\hline Central Perforation & 16 & 45.71 & 24 & 47.05 \\
\hline Attic Perforation & 12 & 34.28 & 18 & 35.29 \\
\hline $\begin{array}{c}\text { Marginal } \\
\text { Perforation }\end{array}$ & 07 & 20 & 17 & 33.33 \\
\hline PTA - AC & & & & \\
\hline $40 \mathrm{~dB}-55 \mathrm{~dB}$ & 13 & 37.14 & 29 & 56.86 \\
\hline $56 \mathrm{~dB}-65 \mathrm{~dB}$ & 22 & 62.85 & 22 & 43.13 \\
\hline Extent of Disease & & & & \\
\hline Limited to Attic & 4 & 11.42 & 18 & 35.29 \\
\hline Attic + Antrum & 7 & 20 & 13 & 25.49 \\
\hline Attic + Antrum+ Tip of Mastoid & 24 & 68.57 & 20 & 39.21 \\
\hline Ossicular Status & & & & \\
\hline M+, I+, S+ & 07 & 20 & 20 & 39.21 \\
\hline M+, I-, S+ & 12 & 34.28 & 17 & 33.33 \\
\hline M+, I-, S- & 16 & 45.71 & 14 & 27.45 \\
\hline Table 2. Showing the Comparison between \\
Group A \& B in Various Clinical, \\
\hline Audiometry and Operative Findings (n = 86) \\
\hline
\end{tabular}

\begin{tabular}{|c|c|c|c|c|c|}
\hline Groups & \multicolumn{2}{|c|}{$\begin{array}{c}\text { Group } \\
\text { A - 35 }\end{array}$} & \multicolumn{2}{c|}{$\begin{array}{c}\text { Group } \\
\text { B - 51 }\end{array}$} & $\begin{array}{c}\text { P } \\
\text { Value }\end{array}$ \\
\hline Observation & No & $\mathbf{\%}$ & No & $\mathbf{\%}$ & \\
\hline Fibrous Tissue & 08 & 22.85 & 36 & 70.58 & 0.015 \\
\hline $\begin{array}{c}\text { Inflammatory } \\
\text { Cellular Infiltration }\end{array}$ & 30 & 85.71 & 45 & 88.23 & 0.0054 \\
\hline PCNA Expression & 32 & 91.42 & 16 & 31.37 & 0.0054 \\
\hline & $\begin{array}{r}\text { Table 3. Showing the HPE, Cellular Infiltrates } \\
\text { and PCNA Expression in Both Groups (n= 86) }\end{array}$ \\
\hline
\end{tabular}

HPE showed no rete ridges, (epidermal thickenings that extend downward between dermal papillae). There were no cellular dysplasias. There was normal nuclear to cytoplasm ratio. The underlying tissues were showing fibrous proliferation in Group B specimens which was significantly higher when compared to Group A patients, but there was no 
difference in cellular inflammatory infiltrates. Lymphocyte, plasma cells and histiocytes infiltration was predominant in the inflammatory infiltrates. Immuno-histochemical examination of the specimens from Group A showed a higher expression of proliferation markers in the matrix and perimatrix (91.42\%) when compared to Group B patients (31.37\%), which was statistically significant with $\mathrm{p}$ values below 0.05 (Table 3). Finally, the clinico-pathological correlation of Group A patients showed aggressive invasion of $\mathrm{CH}$, ossicular destruction, moderate mixed HL compared to Group B patients. The HPE of the $\mathrm{CH}$ matrix and peri-matrix showed more fibrosis in Group B compared to Group A. The cellular infiltrates were equal in both the groups. The immuno-histochemical markers were presenting with a higher expression in Group A compared to Group B.

\section{DISCUSSION}

Acquired cholesteatoma of the middle ear characteristically presents with aggressive growth leading to the destruction of the ossicular chain and other surrounding bony structures. Histologically, a multilayered squamous epithelium (matrix) is surrounded by a mesenchymatous granulation tissue (Perimatrix). The epicenter of the osteolytic process is located in the contact zone between the matrix and perimatrix as well as signs for wound healing with the formation of granulation tissue and capillary multiplication being predominant in the perimatrix. ${ }^{11}$ One can then hypothesise that paediatric and adult cholesteatomas may be representing different spectrums of the same disease or even a different disease entity. As clinically it is difficult to make distinctions between the more and less aggressive cholesteatomas, a study such as this would help to compare the HPE of tissue and quantify the cellular activity in them with the help of immuno-histochemical study was to compare the histopathological structure and cellular proliferates by immuno-histochemical methods. The paediatric $\mathrm{CHs}$ of children in the present study showed a higher incidence of active inflammation as observed by presenting more cellular perimatrix compared to the more fibrotic perimatrix of adult CHS. The degree of fibrosis under the perimatrix was significantly higher in adult $\mathrm{CH}$ specimens. It may suggest that the adult $\mathrm{CHs}$ are more of a wound healing process and so not invasive. At the same time, no difference in the degree of inflammatory infiltration noted between both the groups. Hence, one can assume that the composition of these infiltrates is same in both the groups. No cellular dysplasias or neoplastic changes were observed. These observations are supported by many other authors.12,13,2 Few authors compared only the HPE of CHs of children and adults. They based their studies on histopathological components, perimatrix thickness and degree of inflammation between paediatric and adult CHS. Dornelles ${ }^{14}$ et al showed no differences in the histopathological components of acquired $\mathrm{CH}$ in adults and children in contrast to the present study. Hypothetically, the presence of more fibrosis in adult $\mathrm{CH}$ suggests better control of infection and inflammation giving them better compliance in treatment. In a similar study by Welkoborsky et al,12 authors did not have definite differences between adult and paediatric CHs on the cellular level. Dornelles et al ${ }^{14,15}$ showed that the degree of inflammation of the perimatrix presented moderate to intense correlation with the perimatrix thickness. De Dornelles et al16 used matrix thickness as a parameter of comparison and they found no significant difference between both groups. PCNA is a protein and sub-unit of DNA polymerase with multiple functions such as DNA replication synthesis, DNA repair synthesis and recombination driven DNA synthesis; a triple function in the life and death of the cells. Absence or low levels of functional PCNA may drive cells into apoptosis. ${ }^{17}$ PCNA expression was also tested in middle ear cholesteatoma. Olszewska et al ${ }^{18}$ used PCNA as a marker of proliferation in $\mathrm{CH}$. He found that its expression is significantly higher compared to normal post-auricular skin. Shieh et $\mathrm{al}^{19}$ also showed similar results. In the present study, PCNA was used as a proliferation marker to compare paediatric and adult specimens. PCNA expression was significantly higher in paediatric specimens compared to adult specimens. Increased expression of PCNA signifies increased proliferation, which may be correlated with increased invasiveness and destructive behaviour of paediatric CHs. In the present study, paediatric $\mathrm{CH}$ showed higher markers for PCNA and clinically was more aggressive (Greater extension and more invasions compared to adults). But Hassmann-Poznanska et $\mathrm{al}^{20}$ found no correlation between results of PCNA expression in cholesteatoma and clinical parameters. The contradicting result of different studies with the present study concludes that the increased proliferation alone cannot be the explanation of the aggressive behaviour of paediatric $\mathrm{CHs}$. Therefore, one has to concur with Sade et $\mathrm{al}^{21}$ that the clinically observed aggressive behaviour of paediatric $\mathrm{CH}$ may depend on other parameters such as the disturbance of middle ear ventilation, the preformed paths for $\mathrm{CH}$ extension in the middle ear and/or reduced calcium salt content of the paediatric bone matrix.

\section{CONCLUSION}

Adult cholesteatomas with marked fibrosis in the perimatrix compared to children represent a reparative process at a higher grade and lower invasiveness. Presence of cellular infiltrates equally in both children and adult $\mathrm{CHs}$ suggest an ongoing chronic inflammatory process following infection. Higher expression of PCNA in matrix and perimatrix of children correlate well with their clinical and audiological findings compared to less aggressive adult $\mathrm{CHs}$.

\section{REFERENCES}

[1] Telian SA, Schmalbach CE. Chronic otitis media. In: Snow JB, Ballenger JJ, eds. Ballenger's otorhinolaryngology head and neck surgery. $16^{\text {th }}$ edn. Hamilton, Ontario, BC Decker Inc 2003:261-93.

[2] Albino AP, Kimmelman CP, Parisier SC. Cholesteatoma: a molecular and cellular puzzle. Am J Otol 1998;19(1):7-19.

[3] Aberg B, Westin T, Tjellstrom A, et al. Clinical characteristics of cholesteatoma. Am J Otolaryngol 1991;12(5):254-8.

[4] Ferlito A, Devaney KO, Rinaldo A, et al. Clinicopathological consultation. Ear cholesteatoma versus cholesterol granuloma. Ann Otol Rhinol Laryngol 1997;106(1):79-85.

[5] Lim DJ, Saunders WH. Acquired cholesteatoma: light and electron microscopic observations. Ann Otol Rhinol Laryngol 1972;81(1):1-11. 
[6] Kurihara A, Toshima M, Yuasa R, et al. Bone destruction mechanisms in chronic otitis media with cholesteatoma: specific production by cholesteatoma tissue in culture of bone-resorbing activity attributable to interleukin-1 alpha. Ann Otol Rhinol Laryngol 1991;100(12):989-98.

[7] Wright CG, Meyerhoff WL. Pathology of otitis media. Ann Otol Rhinol Laryngol Suppl 1994;163:24-6.

[8] Kuczkowski J, Kobierska-Gulida G, IzyckaSwieszewska E, et al. Molecular control of bone resorption in chronic otitis media with cholesteatoma. Otolaryngol Pol 2010;64(4):219-24.

[9] Orisek BS, Chole RA. Pressures exerted by experimental cholesteatomas. Arch Otolaryngol Head Neck Surg 1987;113(4):386-91.

[10] Shohet JA, de Jong AL. The management of pediatric cholesteatoma. Otolaryngol Clin North Am 2002;35(4):841-51.

[11] Sudhoff H, Bujia J, Borkowshi G, et al. Basement membrane in middle ear cholesteatoma Immunohistochemical and ultrastructural observations. Ann Otol Rhinol Laryngol 1996;105(10):804-10.

[12] Welkoborsky HJ, Jacob RS, Hinni ML. Comparative analysis of the epithelium stroma interaction of acquired middle ear cholesteatoma in children and adults. Eur Arch Otorhinolaryngol 2007;264(8):841-8.

[13] Mallet $Y$, Nouwen J, Lecomte-Houcke $M$, et al. Aggressiveness and quantification of epithelial proliferation of middle ear cholesteatoma by MIB1. Laryngoscope 2003;113(2):328-31.
[14] Dornelles C, da Costa SS, Meurer L, et al. Correlation of cholesteatomas perimatrix thickness with patients age. Braz J Otorhinolaryngol 2005;71(6):792-7.

[15] Dornelles C, Meurer L, da Costa SS, et al. Histologic description of acquired cholesteatomas: comparison between children and adults. Braz J Otorhinolaryngol 2006;72(5):641-8.

[16] Dornelles Cde C, da Costa SS, Meurer L, et al. Comparison of acquired cholesteatoma between pediatric and adult patients. Eur Arch Otorhinolaryngol 2009;266(10):1553-61.

[17] Paunesku T, Mittal S, Protic M, et al. Proliferating cell nuclear antigen (PCNA): ringmaster of the genome. Int J Radiat Biol 2001;77(10):1007-21.

[18] Olszewska E, Chodynicki S, Chyczewski L, et al. Some markers of proliferative activity in cholesteatoma epithelium in adults. Med Sci Monit 2006;12(8):CR337-40.

[19] Shieh TJ, Ho KY, Kuo WR, et al. Evaluation of proliferative activity in middle ear cholesteatoma using proliferating cell nuclear antigen. Kaohsiung J Med Sci 1999;15(8):468-74.

[20] Hassmann-Poznanska E, Skotnicka B, Dzieciol J. Markers of epidermal proliferation in middle ear cholesteatoma. Otolaryngol Pol 2003;57(4):505-11.

[21] Sade J, Fuchs C. A comparison of mastoid pneumatization in adults and children with cholesteatoma. Eur Arch Otorhinolaryngol 1994;251(4):191-5. 